\title{
Vascularized Fibula Strut Graft Used in Neurofibromatosis Type 1-Related Kyphosis: A Case of Almost Complete Reversal of Deformity-Induced Tetraparesis
}

\author{
Markus Melloh ${ }^{1}$ Bruce Hodgson ${ }^{2}$ Alan Carstens ${ }^{2}$ Jon Cornwall ${ }^{3}$ \\ ${ }^{1}$ Western Australian Institute for Medical Research (WAIMR), \\ University of Western Australia, Nedlands, Western Australia, \\ Australia \\ 2 Department of Orthopaedic Surgery, Dunedin Public Hospital, \\ Address for correspondence Markus Melloh, MD, MPH, PhD, MBA, \\ Western Australian Institute for Medical Research (WAIMR), University \\ of Western Australia, B Block, QEII Medical Centre, Hospital Avenue, \\ Nedlands, WA 6009, Australia (e-mail: markus.melloh@uwa.edu.au).
} Dunedin, New Zealand

${ }^{3}$ Department of Anatomy, University of Otago, Dunedin, New Zealand

Evid Based Spine Care J 2013;4:59-62.

\begin{abstract}
Study Design Case report.

Objective The aim of this study is to describe a case of vascularized fibula strut graft implanted in the cervicothoracic spine of a patient with neurofibromatosis type 1-related progressive kyphosis.

Methods A detailed history examination of the surgical procedures and the results of the follow-up after fibula strut graft implantation were performed. In addition, a review of the literature was conducted to access the incidence of similar cases with an almost complete reversal of a deformity-induced tetraparesis.

Results A 37-year-old man with severe type 1 neurofibromatosis causing a collapsing kyphosis of the cervicothoracic spine presented in 2006 with progressive low cervical tetraparesis. Intervention included posterior stabilization ( $C 5$ to T5) which was extended to C3-T9 in 2008; however, the kyphosis continued to worsen. In 2009, a vascularized fibula strut graft was implanted between the inferior and superior endplates of C3 and T9. Over the following months, the patient gradually recovered motor strength and improved functional use of all limbs. In March 2011, lower limb (bilateral) and right arm

Keywords

- neurofibromatosis

- cervical spine

- kyphosis

- tetraparesis

strength was grade 5 , with left arm strength being grade $4+$.

Conclusions This case report demonstrates the existence of a potential local option for the difficult problems of pseudoarthrosis, progressive spinal deformity, and cord compromise in patients with neurofibromatosis type 1-related kyphosis resulting in an almost complete reversal of deformity-induced tetraparesis.
\end{abstract}

\section{Introduction}

Progressive deformity of the vertebral column can have serious neurological and functional consequences, with neurofibromatosis among those conditions known to cause spinal degeneration that constitutes significant surgical challenges. ${ }^{1}$ As a result of neurofibromatosis-related deformity, mechanical failure of

received

September 30, 2012

accepted after revision

November 28, 2012

the spine may contribute to radiculopathy- or myelopathyrelated outcomes such as tetraparesis or tetraplegia. ${ }^{1}$

In many instances, stabilization of the vertebral column can be achieved through posterior fixation; however, in some instances, posterior fixation is either not mechanically viable or subsequently proved inadequate through breakage. In these instances, the options for preventing on-going deformity and

(c) 2013 Georg Thieme Verlag KG Stuttgart · New York
DOI http://dx.doi.org/ 10.1055/s-0033-1341599. ISSN 1663-7976. 
neurological compromise are limited, with anterior stabilization via fibula strut graft providing one such option. We report a unique case where a fibula strut graft resulted in an almost complete reversal of a deformity-induced tetraparesis.

\section{Case Report}

A 37-year-old man with severe type 1 neurofibromatosis causing a collapsing kyphoscoliosis of the cervicothoracic spine presented in 2006 with progressive low cervical tetraparesis and a partial loss of bladder and bowel function. Intervention included posterior stabilization (C5 to T5; 2006) which failed mechanically with pseudoarthrosis after 1 year. This was repeated (C3 to T9; November 2008); however, the kyphosis continued to worsen.

Further surgery to stabilize the vertebral column was indicated because of increasing tetraparesis, aiming to prevent further collapse of the vertebral column, reverse spatial compromise of the neural canal, and relieve pressure on the spinal cord (-Figs. 1a, b). A fibula strut graft was performed in an attempt to stabilize the anterior aspect of the cervicothoracic spine and reverse tetraparesis.

In April 2009, a vascularized fibula strut graft was performed. The harvested graft was mechanically secured between the inferior and superior endplates of C3 and T9 (-Fig. 2), respectively, and the vascular pedicle anastomosed with contributions from the facial artery and vein. Postsurgery, the graft became integrated and remained vascular. Over the following months, the patient gradually recovered bladder and bowel function, motor strength, and improved functional use of all limbs. On examination (March 2011), lower limb (bilateral) and right arm strength was grade 5, with left arm strength being grade $4+$.

\section{Discussion}

Fibula strut grafts have been used for decades as an option for anterior spinal stabilization. ${ }^{2}$ Previous reports indicating the reversal or improvement of symptoms arising from neural compromise are potential outcomes of this procedure, particularly when utilized in conjunction with other interventions such as discectomy or corpectomy., ${ }^{3,4}$ However, no previous cases of fibula strut graft implementation have reported the reversal of such significant cord compromise as seen in this patient.

This is, therefore, the first documented New Zealand case where this technique has been successfully performed in the deformed cervicothoracic spine to reverse tetraparesis and recover significant neurological function. The outcome was achieved by preventing further mechanical displacement of the vertebral column, with the successful graft surviving via patent vascular anastomosis, thereby ensuring the continued performance and integrity of the graft material. It demonstrates the existence of a potential local option for the difficult problems of pseudoarthrosis, progressive spinal deformity, and cord compromise.
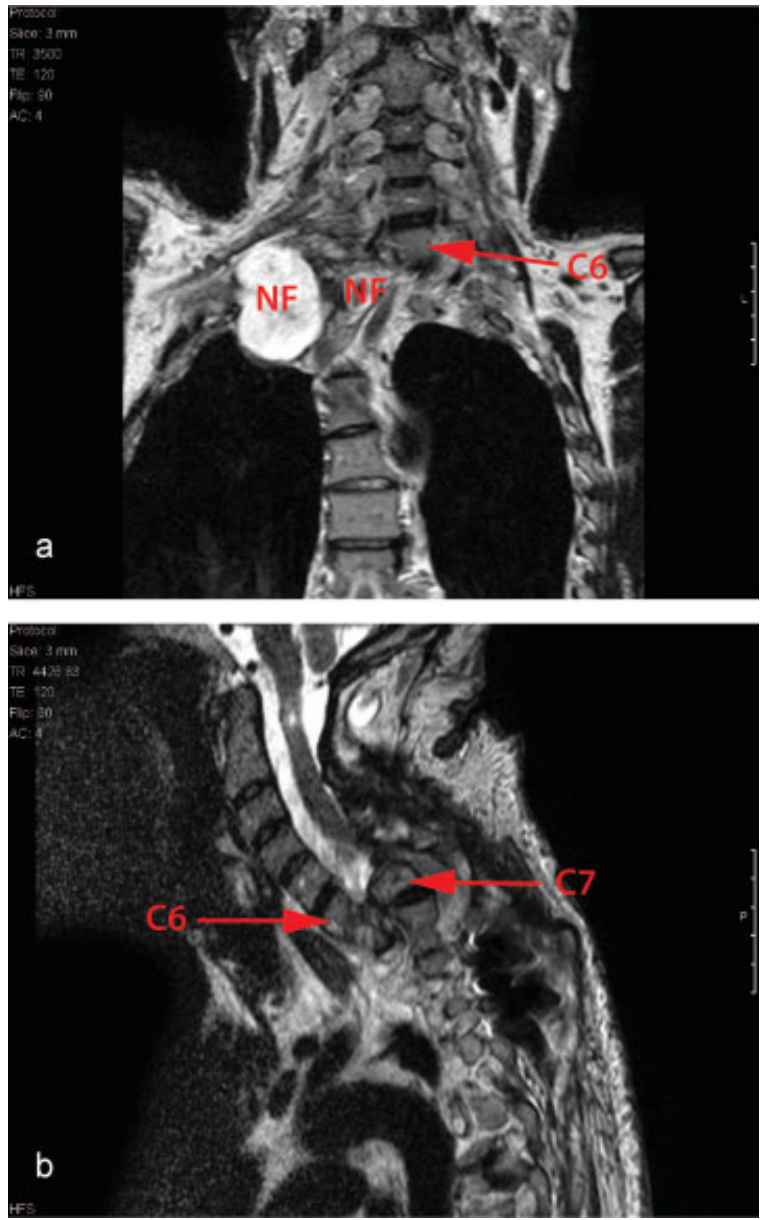

Fig. 1 (a) Frontal preoperative image of patient's cervicothoracic spine. Frontal MRI scan of the cervical spine showing cervical translocation and lack of anterior structural support with multiple large neurofibroma. Vertebral levels are as indicated. NF, neurofibroma. (b) Sagittal preoperative image of patient's cervicothoracic spine. Sagittal MRI scan of the cervical spine showing cervical translocation and lack of anterior structural support. Vertebral levels are as indicated.

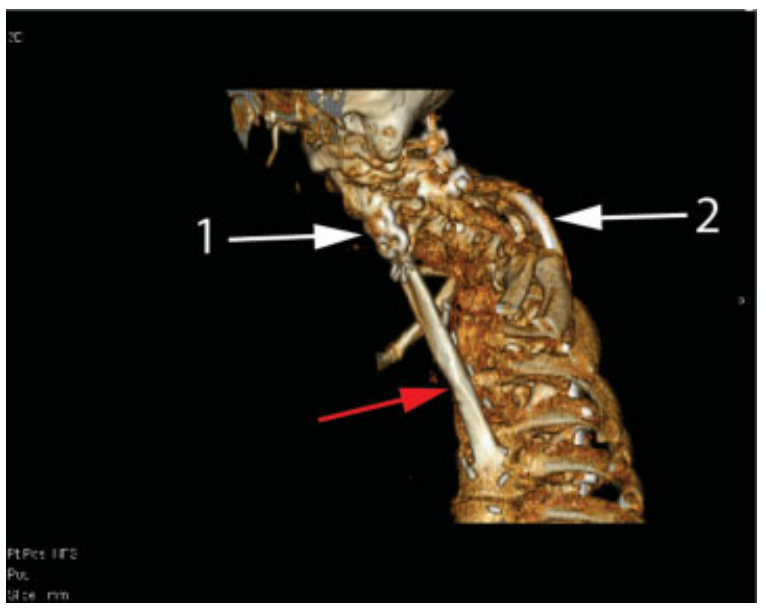

Fig. 2 Postoperative image of fibula strut graft in-situ. Threedimensional image reconstruction (left-lateral) showing fibula strut graft in situ (red arrow). 1. Location of anterior buttress plate for seating the fibula. 2. Previous fixation device. 


\section{Conflict of Interest}

None

\section{Ethics}

Approval for this case report was provided by the Lower South Ethics Committee.

\section{Acknowledgments}

The authors would like to gratefully acknowledge the kind permission and consent of the patient.

\section{References}

1 Taleb FS, Guha A, Arnold PM, Fehlings MG, Massicotte EM. Surgical management of cervical spine manifestations of neurofibromatosis Type 1: long-term clinical and radiological follow-up in 22 cases. J Neurosurg Spine 2011;14(3):356-366

2 Whitecloud TS, Larocca H. Fibular strut graft in reconstructive surgery of the cervical spine. Spine (Phila Pa 1976) 1976;1: 33-43

3 Yonenobu K, Fuji T, Ono K, Okada K, Yamamoto T, Harada N. Choice of surgical treatment for multisegmental cervical spondylotic myelopathy. Spine (Phila Pa1976) 1985;10(8):710-716

4 Martus JE, Griffith TE, Dear JC, Rathjen KE. Pediatric cervical kyphosis: a comparison of arthrodesis techniques. Spine (Phila Pa 1976) 2011;36(17):E1145-E1153 


\section{Editorial Perspective}

The EBSJ Editorial Board appreciates the submission of this extraordinary case. As expressed in Dr. Vialle's commentary, this is a highly unusual case with little or no structured guidance available from the body of literature; most of the more advanced cases of NF-1 seem to require a one-out type of problem solving. The solution provided in this case presentation is certainly impressive, yet it bears all the implications associated with a "maximally invasive" procedure. It is a morbid approach, and a free vascularized tissue transfer with well-known donor site morbidity adds the need for postoperative anticoagulation in a patient who will already be at an elevated risk for perioperative bleeding due to the disease process and revision spinal surgery. The authors did a fine job for sure and found a suitable and likely lasting solution for this patient. The general literature as quoted in Dr. Vialle's commentary is a sobering one, however, with complication rates between 42 and $85 \%$ quoted for the more

\section{Commentary}

\author{
Luis R. Vialle ${ }^{1}$ \\ ${ }^{1}$ Grupo de Coluna/Spine Unit, Universida de Católicado Paraná, \\ Curitiba, Brasil
}

The authors have chosen to stabilize a cervicothoracic kyphosis by means of a strut graft after two attempts of posterior stabilization. No comments were drawn regarding a laminectomy or osteotomy or on the type of instrumentation used. The anterior approach to the cervicothoracic junction is fraught with pitfalls, from planning to execution. ${ }^{1}$ Depending on the patient's anatomy, wide dissection on the thoracic cage and dissection of the major vessels is necessary. Extending it from the cervical spine through the midthoracic spine is a major surgery. The potential for graft displacement warrants major complication risk, for vascular and esophageal injuries. The presence of dystrophic features (not mentioned by the authors) increases the risk of kyphosis progression, and one would expect failure of a posterior approach if the patient is managed like a nondystrophic deformity. ${ }^{2-5}$

In our opinion, the posterior approach allows for rigid, multilevel fixation, direct visualization of the spinal cord (as well as duralectasia and neurofibromas). Depending on the degree of kyphosis, a combination of Ponte and pedicle subtraction osteotomies or vertebral column resection can be performed to not only decompress but to realign the cervicothoracic junction without lengthening of the cord. In the presented case, a vertebral column resection would allow for a change in the load distribution over the spine and reduce the risk of posterior approach failure. ${ }^{6}$

Although not mentioned in the text, neuromonitoring is crucial to any acute angle kyphosis correction, since even positioning can cause neurologic impairment in such cases. involved cases. In the bigger picture, this type of case bears great application potential for a registry use. Rare index cases like this collected from centers around the world could over a few short years allow for relevant data mining and offer new clues as to assessment, treatment, and outcomes. What it takes to get there: several key figures in centers that see these types of patients and are willing to systematically standardize their assessment, data gathering, and reporting mechanisms while minimizing treatment variability and combine their data for collective analysis. Fortunately, we have such a model existing now: The Knowledge Forum opportunity allows for such an effort in a global and interdisciplinary fashion. Clearly, there is room for a global NF project either in a Deformity or a Neoplasia group to be started. We hope that reading these lines will motivate all readers to engage with AOSpine and to contribute to our larger body of knowledge!
For avoiding the failure of the previous posterior procedures, the authors always assume NF patients as high-risk for nonunion, and using double rods at transitional levels, as well as prescheduled revision of the fusion mass at the sixth postoperative month. ${ }^{3,4}$

NF presents in many different ways, and literature is not able to offer strict guidelines. I would like to commend the authors for their innovative solution on revising such a complex case.

\section{References}

1 Falavigna A, Righesso O, Pinto-Filho DR, Teles AR. Anterior surgical management of the cervicothoracic junction lesions at $\mathrm{T} 1$ and $\mathrm{T} 2$ vertebral bodies. Arq Neuropsiquiatr 2008;66(2A):199-203

2 Crawford AH. Pitfalls of spinal deformities associated with neurofibromatosis in children. Clin Orthop Relat Res 1989; (245):29-42

3 Winter RB, Lonstein JE, Anderson M. Neurofibromatosis hyperkyphosis: a review of 33 patients with kyphosis of 80 degrees or greater. J Spinal Disord 1988;1(1):39-49

4 Winter RB, Moe JH, Bradford DS, Lonstein JE, Pedras CV, Weber AH. Spine deformity in neurofibromatosis. A review of one hundred and two patients. J Bone Joint Surg Am 1979;61(5): 677-694

5 Wilde PH, Upadhyay SS, Leong JC. Deterioration of operative correction in dystrophic spinal neurofibromatosis. Spine (Phila Pa 1976) 1994;19(11):1264-1270

6 Lenke LG, O’Leary PT, Bridwell KH, Sides BA, Koester LA, Blanke KM. Posterior vertebral column resection for severe pediatric deformity: minimum two-year follow-up of thirty-five consecutive patients. Spine (Phila Pa 1976) 2009;34(20):2213-2221 